\title{
Comparison of different methods to predict the mean flow velocity in step-pool channels
}

\author{
T. Michelini, V. D'Agostino \\ University of Padova, Dept. TeSAF, Legnaro (PD),, Italy
}

\begin{abstract}
Steep mountain streams have irregular bed topography, where the mean flow velocity is heavily affected by the coarsest bed components and by their arrangement to form step pools, cascades, and rapids. According to literature findings the mean flow velocity is often related with water discharge, channel slope, and grain-size related variables through power relationships. Several approaches consider dimensionless hydraulic geometry terms to develop the analysis over a wide range of channel sizes and hydraulic conditions. The aim of this research is to test the performance of some literature formulas to directly compute the mean flow velocity $(V)$ in step-pool sequences.

The study area deals with two fish ladders located in the Vanoi torrent (Trento Province, Italy), which were built by mimicking the steppool morphology. Three reaches were selected to cover different channel slopes (2.6-10\%). Data collection entailed three main phases: (1) topographical surveys, (2) granulometric analysis, and (3) flow discharge measurements (salt dilution method). Geometric and hydraulic variables were measured for the following step-pool cross sections: step head, pool center, and intermediate position between pool end next step. Particular attention has been reserved to determine the effective mean flow velocity over the whole path of each step pool sequence. The performance of different literature equations to predict $\mathrm{V}$ has been verified. The relations have been shared in three groups: dimensional $(V)$, dimensionless with respect to the grain size $\left(V^{*}\right)$ or to a combination of grain size and slope $\left(V^{* *}\right)$. In general, the $V$ group of equations has produced the highest errors between computed and measured values. The dimensionless $V^{*}, V^{* *}$ groups have shown the best performance. In particular the $V^{*}$ equations, which use unit discharge and channel slope, have provided the better fitting, and the lowest root mean square error. The results highlight the difficult to estimate flow velocity in step-pool sequences, and the attitude of this channel-bed morphology to be highly dissipative. The good performance of some dimensionless equations to predict $V$ could also support
\end{abstract}

\footnotetext{
Correspondence: Tamara Michelini, University of Padova, Dept. TeSAF

Viale dell'Università, 16 - 35020 Legnaro (PD), Italy.

Tel. +39.049.8272700 - Fax +39.049.8271686

E-mail: tamara.michelini@studenti.unipd.it

Key words: flow velocity, morphology, steep channels; step-pool]

(C) Copyright T. Michelini and V. D'Agostino, 2013

Licensee PAGEPress, Italy

Journal of Agricultural Engineering 2013; XLIV(s2):e24

doi:10.4081/jae.2013.s2.e24
}

This article is distributed under the terms of the Creative Commons Attribution Noncommercial License (by-nc 3.0) which permits any noncommercial use, distribution, and reproduction in any medium, provided the original author(s) and source are credited. the hydraulic designer in case the 'morphological rebuilding' of mountain creeks is opportune. Further analyses are required to better understand the flow behavior in streams where very rough bed forms and hydraulic drops are the primary sources of flow energy dissipation.

\section{Introduction}

In mountain environments, alluvial channels with gradients greater than 0.02 (Grant et al., 1990) can form step-pool sequences, which are characterized by large-scale roughness. Step-pools are functionally important in river systems because they maximize flow resistance and increase the bed stability (Abrahams et al., 1995; Chin, 2003; Curran and Wohl, 2003; MacFarlane and Wohl, 2003). The step-pool regime alternates supercritical and subcritical flow conditions and results very similar to that of consolidation check-dams. Previous investigations suggest that the step-pool reach gradient (S) and liquid discharge represent dominant controls of the flow kinematic of mountain creeks (David et al., 2010). In field study of rough and narrow streams the flow discharge measurement is usually more accurate than the flow depth measurement. In fact, these streams exhibit irregular bed topography that makes difficult the determination of a representative flow depth (Rickenmann and Recking, 2011). Consequently several authors have calibrated equation for the direct estimation of the mean flow velocity (V) using both field data (Jarrett, 1984; Rickenmann, 1994; Ferguson, 2007; Comiti et al., 2007) and laboratory data on self-formed steps (Comiti et al., 2009; Zimmermann, 2010). These equations have the following form:

$$
V \propto g^{0.20} S^{0.20} q^{0.60} D_{c}{ }^{-0.40}
$$

where $\mathrm{q}$ is the unit discharge, $D_{c}$ the grain roughness, and $\mathrm{g}$ the gravity acceleration. Rickenmann (1991) proposed to use $D_{c}=D_{90}$ (diameter for which the $90 \%$ of the sieve diameter is finer), while Aberle and Smart (2003) and Zimmermann (2010) adopted the standard deviation of bed longitudinal profile $\left(\sigma_{z}\right)$, resulting more appropriate in streams with substantial bed forms.

Comiti et al. (2007) introduced the hydraulic geometry equation in a dimensionless form:

$$
V^{*}=a q^{* m}
$$

being $\alpha$ and $m$ two empirical parameters and:

$$
\begin{aligned}
& V^{*}=\frac{V}{\sqrt{g D_{c}}} \\
& q^{*}=\frac{q}{\sqrt{g D_{c}{ }^{3}}} .
\end{aligned}
$$

Ferguson (2007) has remarked that [Eq. 2] performs better than other equations since $q^{*}$ is a better predictor than the depth $(h)$ over 
grain size ratio $\left(h / D_{c}\right)$ and is probably less affected by measure error.

Rickenmann and Recking (2011) introduced the following new dimensionless terms:

$$
\begin{aligned}
V^{* *} & =\frac{V}{\sqrt{g S D_{c}}} \\
q^{* *} & =\frac{q}{\sqrt{g S D_{c}{ }^{3}}}
\end{aligned}
$$

and then they formulated a hydraulic-geometry type equation:

$$
I^{* *}=a q^{* * m}
$$

The authors calibrated equation [Eq. 7] through a data set of 2890 field measurements. They divided the result into three different domains as to $q^{* *}\left(q^{* *} \geq 100 ; 1 \leq q^{* *}<100 ; q^{* *}<1\right)$. To obtain a smoother transition for the velocity predictions between the three domains, the authors used the logarithmic matching technique proposed by Guo (2002). The aim of this research is to test the predictive capacity of available literature formulas, which are more appropriate to compute directly the mean flow velocity in channels with a step-pool morphology. The verification has been carried out by using field data of small-scale step-pool sequence and assessing the performance of the equations listed in Table 1.

\section{Materials and methods}

A dataset of hydraulic and geometric variables were collected in three artificial step-pool reaches, which were built with the function of fish ladders by passing check dams in the Vanoi torrent (Trento Province, Italy). Three step-pool reaches (TA, TB, TS; channel widths from 0.62 to $1.65 \mathrm{~m}$ ) were selected in order to test different channel slopes $(6.0 \%, 10.0 \%$, and $2.6 \%$ respectively). Field experiments were performed in three main phases: (1) topographical surveys, to draw longitudinal profiles and cross-sections of the channel; (2) grain-size measures of the bed surface; the sediment sampling was conducted by line (fixed spacing) and using a caliber; (3) measurements at controlled steady conditions of flow depth and water discharge using the salt dilution method. A number of 65 cross-sections were surveyed in the following characteristics positions: step heads ( $\mathrm{SH})$, pool centers (PC), and intermediate positions (INT) between the pool end and the following step. The mean flow velocity (V) in each cross-section was back-calculated as the ratio discharge (Q) flow area (A). In the elaboration of field data particular attention was reserved to quantify the effective mean flow velocity over the whole path of each step-pool reach. This velocity, here defined as 'reach-averaged flow velocity', resulted from the ratio between the sequence length and the total travel time, which was calculated accounting for partial mean velocities within the all sub-reaches SH-PC, PC-INT, and INT-SH. The reach-averaged $\mathrm{V}$ values were compared with $\mathrm{V}$ values that can be computed via the

Table 1. Equations for flow velocity prediction tested in this study; $\mathbf{R h}=$ hydraulic radius; $\mathbf{h m}=$ hydraulic depth (m); $\mathbf{H} / \mathbf{L}=$ step height-length ratio; $\sigma_{z}$

\begin{tabular}{|c|c|}
\hline Matakiewickz (1932) & $V=2.38 R h^{0.70}$ \\
\hline Bray (1979) & $V=8 R h^{0.60} S^{0.29}$ \\
\hline Jarrett (1984) & $V=3.17 R h^{0.83} S^{0.12}$ \\
\hline Rickenmann (1991) & $V=1.3 g^{0.20} S^{0.20} q^{0.60} D_{90}^{-0.40}$ \\
\hline Rickenmann (1994) & $V=0.37 g^{0.33} S^{0.20} Q^{0.34} D_{90}^{-0.35}$ \\
\hline Aberle and Smart (2003) & $V=0.96 g^{0.20} S^{0.20} q^{0.60} \sigma_{z}^{-0.40}$ \\
\hline D'Agostino (2005) & $V=1.42 q^{0.48}$ \\
\hline D'Agostino et al. (2006) & $V=1.21 g^{0.245} S^{0.16} q^{0.51} D_{84}^{0.265}$ \\
\hline Comiti et al. (2007) & $V^{*}=0.29 q^{* 0.66}$ \\
\hline Comiti et al. (2007) & $V^{*}=0.74 q^{* 0.59}\left(\frac{H / L}{S}\right)^{0.52}$ \\
\hline Ferguson (2007) & $V^{*}=1.44 q^{* 0.60} S^{0.2}$ \\
\hline Comiti et al. (2009) & $V^{*}=1.24 q^{* 0.83}$ \\
\hline Zimmermann (2010) & $V^{*}=0.58 q^{* 0.39}$ \\
\hline Yochum et al. (2012) & $V^{* *}=q^{* * 0.16}$ \\
\hline Yochum et al. (2012) & $V^{* *}=0.9\left(\frac{h m}{\sigma_{z}}\right)^{* * 0.16}$ \\
\hline Rickenmann and Recking (2011) & $V^{* *}=1.5471 q^{* * 0.7062}\left[1+\left(\frac{q^{* *}}{10.31}\right)^{0.6317}\right.$ \\
\hline
\end{tabular}
= standard deviation of the residuals of a thalweg longitudinal profile regression (m); $\mathrm{D}_{90}$ (diameter for which the $90 \%$ of the sieve diameter is finer) (see text for the other symbols). 
relationships listed in Table 1. Observed values were then plotted against measured values. The predictive performance of each equation was assessed by means of the normalized root mean square error (RMS), quantifying the following standard deviation of residuals:

$$
R M S=\sqrt{\frac{\sum\left(\frac{V_{\text {predicted }}-V_{\text {observed }}}{V_{\text {predicted }}}\right)^{2}}{N}}
$$

\section{Results}

The main results of topographical surveys, granulometric analysis and flow measurements are summarized in Table 2 and Table 3. The reach-averaged $\mathrm{V}$ data versus predicted values are shown in Figure 1 along with $R M S$, which was calculated both separately for each reach (TA, TB, TS) and for the whole sample (Tot in Figure 1). All comparisons and performance evaluations were conducted in terms of dimensional flow velocity $(\mathrm{V})$, thus always transforming the equation results
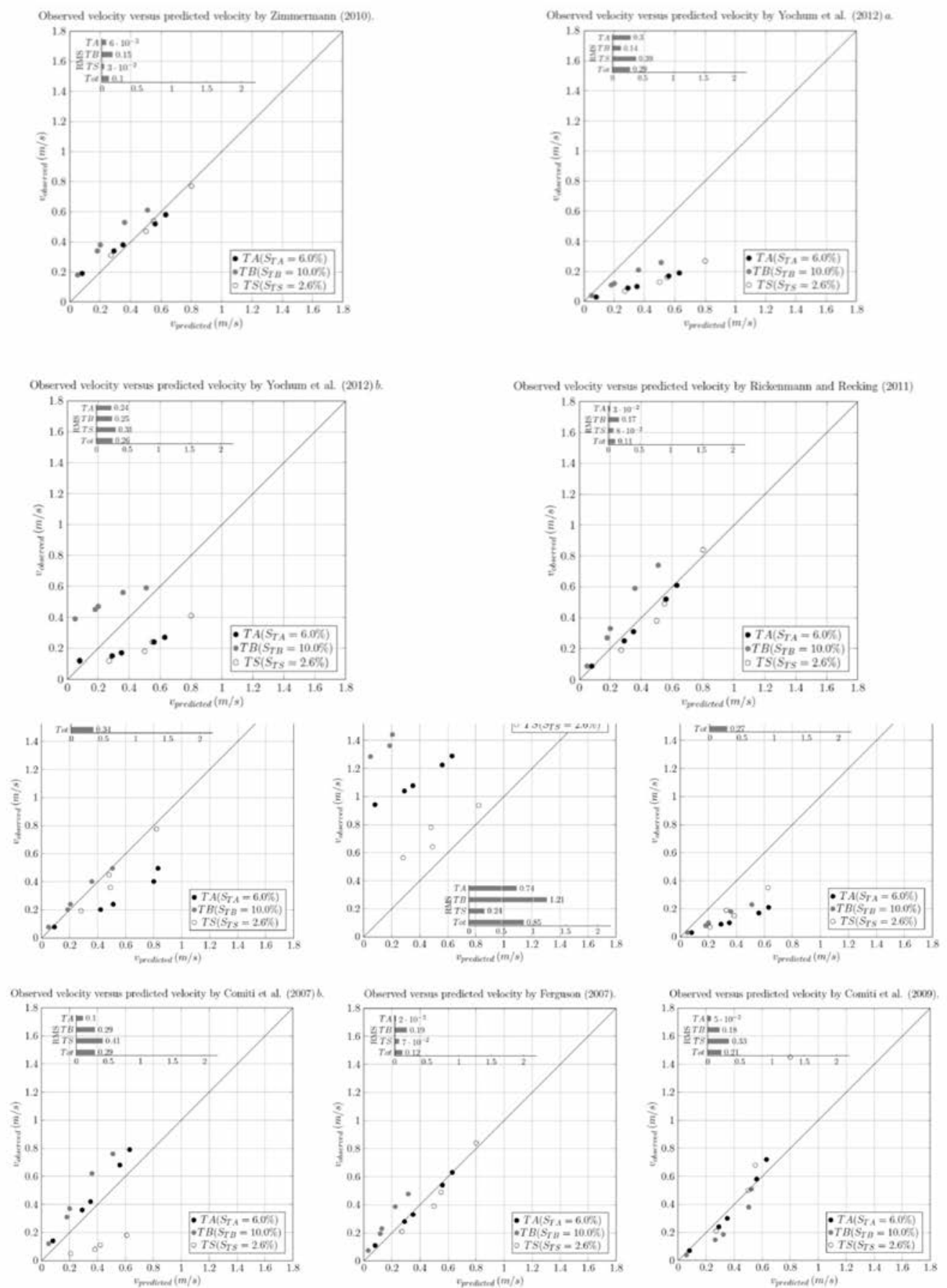

Figure 1. Observed values of mean flow velocity $\left(V_{\text {observed }}\right)$ versus predicted values $\left(V_{\text {predicted }}\right)$ from the application of equations in Table 1. 
of those equations (e.g. Eq. [17] or [23], Table 1), which adopt dimensionless variables.

Between the classical power law relationships directly computing the mean velocity $(V)$, the D'Agostino (2005) equation provided predictions with the best performance (lowest $R M S=0.297$ ). Considering the equations based on the $V^{*}$ group, that of Zimmermann (2010) produced the lowest $R M S(0.098)$ and this value was also the best one on the whole $\left(\mathrm{V}, \mathrm{V}^{*}\right.$ and $\mathrm{V}^{* *}$ group). A quite similar $R M S$ value (0.121) resulted from the relations of Ferguson (2007) and Comiti et al. (2009), and both equations showed a general tendency to an overestimation. Analysing the dimensionless $V^{* *}$ group of equations, the lowest $R M S$ (0.109) was generated by the equation of Rickenmann and Recking (2011), with a RSM value very close to that Zimmermann (2010). Equation 22, proposed by Yochum et al. (2012), is the only one containing a relative submergence, and exhibited a tendency of underestimation. Comiti et al. (2007) equation, which employs a steepness factor, produced a high dispersion of data around the line of perfect agreement.

Looking at the three reaches (TA,TB, and TS) separately, the Ferguson (2007) equation provided the lowest $R M S(0.020)$ and the best fit for the reach TA. Good predictions for the reach TA was also obtained with Rickenmann and Recking (2011) and Comiti et al. (2009) relations. For the reach $T B$, Yochum et al. (2012), equation [21], and Zimmermann (2010) predicted the more correct values. It was also observed that the dimensionless equation introduced by Zimmermann (2010) provided the lowest sum of the three partial $R M S$ values.

Table 2. Principal results of topographical and grain-size measurements.

\begin{tabular}{lccccc} 
Reach & Cross-sections & $\begin{array}{c}\text { Total Length } \\
(\mathrm{m})\end{array}$ & $\begin{array}{c}\text { Slope } \\
(\mathrm{m} / \mathrm{m})\end{array}$ & $\begin{array}{c}\mathrm{D}_{84} \\
(\mathrm{~m})\end{array}$ & $\begin{array}{c}\sigma \\
(\mathrm{m})\end{array}$ \\
$\mathrm{TA}$ & 22 & 35.39 & 0.060 & 0.26 & 0.244 \\
TB & 19 & 19.99 & 0.100 & 0.26 & 0.279 \\
\hline TS & 23 & 42.98 & 0.026 & 0.18 & 0.078 \\
\hline
\end{tabular}

Table 3. Data set of the experiments in the artificial step-pool reaches.

\begin{tabular}{lccc}
$\begin{array}{l}\text { Reach } \\
\text { aged }\end{array}$ & $\begin{array}{c}\text { Eischarge } \\
\text { Q }\left(\mathrm{m}^{3} / \mathrm{s}\right)\end{array}$ & $\begin{array}{c}\text { Reach-ave } \\
\text { flow velocity } \\
\text { V (m/s) }\end{array}$ \\
TA & TA_1 & 0.01 & 0.627 \\
& TA_2 & 0.03 & 0.048 \\
& TA_3 & 0.04 & 0.185 \\
& TA_4 & 0.12 & 0.204 \\
TB & TA_5 & 0.18 & 0.357 \\
& TB_1 & 0.01 & 0.505 \\
& TB_2 & 0.03 & 0.275 \\
& TB_3 & 0.04 & 0.492 \\
& TB_4 & 0.11 & 0.426 \\
TS & TB_5 & 0.19 & 0.823 \\
& TS_1 & 0.01 & 0.069 \\
& TS_2 & 0.04 & 0.151 \\
& TS_3 & 0.07 & 0.224 \\
& TS_4 & 0.23 & 0.412 \\
\hline
\end{tabular}

\section{Discussions and conclusions}

The capability to predict the mean flow velocity $\mathrm{V}$ for a given discharge is essential for hydraulic and hydrological modelling, stream restoration design, geomorphic analysis, and ecological studies (Yochum et al., 2012). An unique approach is not available to predict $\mathrm{V}$ in each fluvial-morphological type, and, in particular, in steep channels. As to step-pool sequences the application of traditional laws of flow resistance provides serious problems because the $V$ estimation is highly sensitive to the choice of representative cross-sections and roughness parameters due to great irregularity of thalweg and stream banks. Therefore, when the discharge is known, the direct estimation of $\mathrm{V}$ from the unit water discharge is preferable (Rickenmann, 1990; Aberle and Smart, 2003; D'Agostino, 2005; Ferguson, 2007). In this research, a new database of cross section geometry and hydraulic variables was collected for small-scale step pools under well controlled steady flow conditions. The mean flow velocity has been extracted in terms of a reach-averaged velocity resulting from the 'travelling' time along the whole step-pool sequence. The study results indicate the dimensionless unit discharge, [Eq. 4 ], is a robust predictor of $\mathrm{V}$ over a significant range of step-pool slopes (3-10\%). The Zimmermann (2010) equation generated the best fit and the lowest errors, hinting that the used roughness parameter $\left(D_{c}=\sigma_{z}\right)$ is more suitable for the $\mathrm{V}$ assessment in step-pools. Furthermore Yochum et al. (2012) equation, [Eq. 22], which also contains $\sigma_{z}$ and well predicts $V$, confirms the previous remark. In few words, the standard deviation $\sigma_{z}$ of the residuals of the thalweg profile regression allows capturing the influence of the largest clast on the flow resistance and then avoiding a more problematic grain size sampling. The good performance of Rickenmann and Recking (2011), Comiti et al. (2009), and Ferguson (2007) equations has turned out to be in accordance with Comiti et al. (2007) and David et al. (2010) findings. In fact, our study confirms that variations in flow resistance are mostly explained by unit discharge and slope, whereas the relative submergence $h m / D_{84}$ is not an appropriate explanatory variable of $\mathrm{V}$ for step-pool creeks, and a macro-roughness variable, like the step heightlength ratio, can be more effective. Finally, the good predictions provided by the Rickenmann and Recking (2011) equation for the three steppool reaches suggest to better investigate on the transitional behaviour between shallow and deep flows and to dedicate further efforts in assessing the boulder concentration and protrusion (Nitsche et al., 2012), which interact with such a transition.

\section{References}

Aberle J., Smart G. M. 2003. The influence of roughness structure on flow resistance on steep slopes. J. Hydraul. Res., 41(3): 259-269.

Abrahams A. D., Li G., Atkinson J. F. 1995. Step-pool streams: adjustment to maximum flow resistance. Water Resour. Res. 31: 25932602, doi:10.1029/95WR01957.

Chin A. 2003. The geomorphic significance of step-pools in mountain streams. Geomorphology, 55: 125-137.

Comiti F., Cado D., Wohl E. 2009. Flow regimes, bed morphology, and flow resistance in self-formed step-pool channels. Water Resour. Res. 45: W04424, doi:10.1029/2008WR007259.

Comiti F., Mao L., Wilcox A., Wohl E. E., Lenzi M. A. 2007. Field- derived relationships for flow velocity and resistance in high-gradient streams. J. Hydrol., 340: 48-62, doi:10.1016/j.jhydrol.2007.03.021.

Curran J. H., E. E. Wohl 2003. Large woody debris and flow resistance in step-pool channels, Cascade Range, Washington. Geomorphology, 51: 141-157, doi:10.1016/S0169-555X(02)00333-1. 
D’Agostino V. 2005. Velocità media della corrente in torrenti fortemente scabri. In: Proc. of the Italian Congress AIIA2005, Catania, Italy, June: 27-30.

David G. C. L., Wohl E. E., Yochum S. E., Bledsoe B. P. 2010. Controls on spatial variations in flow resistance along steep mountain streams. Water Resour. Res., 46(3): W03513, doi:10.1029/2009WR008134.

Ferguson R. 2007. Flow resistance equations for gravel- and boulderbed streams. Water Resour. Res., 43(12): W05427, doi:10.1029/2006 WR 005422 .

Grant G. E., Swanson F. J., Wolman M. G. 1990. Pattern and origin of stepped-bed morphology in high- gradient streams. Western Cascades, Oregon. Geol. Soc. Am. Bull., 102: 340-352.

Guo J. 2002. Logarithmic matching and its application in computational hydraulics and sediment transport. J. Hydraul. Res., 40(5): 555566.

Jarrett R. D. 1984. Hydraulics of high-gradient rivers. J. Hydraul. Eng., 110(11): 1519-1539.

MacFarlane W. A., Wohl E. E. 2003. Influence of step composition on step geometry and flow resistance in step-pool streams of the Washington Cascades. Water Resour. Res., 39(2): 1037, doi:10.1029/2001WR001238.

Nitsche M., Rickenmann D., Turowski J. M., Badoux A., Kirchner J.W. 2011. Evaluation of bedload transport predictions using flow resistance equations to account for macro-roughness in steep mountain streams. Water Resour. Res., 47(8): W08513, doi:10.1029/2011 WR010645.

Rickenmann D. 1991. Hyperconcentrated flow and sediment transport at steep slopes. J. Hydraul. Eng., 117(11): 1419-1439.

Rickenmann D. 1994. An alternative equation for the mean velocity in gravel-bed rivers and mountain torrents. In: G. V. Cotroneo, R. R. Rumer (eds.), Hydraulic Engineering, vol. 1, Am. Soc. of Civ. Eng., New York, pp. 672-676.

Rickenmann D. 1990. Bedload transport capacity of slurry flows at steep slopes. Mitt. der Versuchsanstalt fur Wasserbau, Hydrologie und Glaziologie, ETH Zurich, 103.

Rickenmann D., Recking A. 2011. Evaluation of flow resistance in gravel-bed rivers through a large field data set. Water Resour. Res. 47(7): W07538, doi:10.1029/2010WR009793.

Yochum S. E., Bledsoe B. P., David G. C. L., Wohl E. E. 2012. Velocity prediction in high-gradient channels. J. Hydrol., 424: 84-98, doi:10.1016/j.jhydrol.2011.12.031.

D’Agostino V., Zasso M., Vianello A., Cesca M. (2005). Nuovi contributi sulla velocità media della corrente nei corsi d'acqua montani. Quaderni di Idronomia Montana, 25, Bios, Cosenza, pp. 117-129 (ISBN - 10: 88-60-93-014-6).

Zimmermann A. 2010. Flow resistance in steep streams: An experimental study, Water Resour. Res., 46: W09536, doi:10.1029/2009WR 007913. 